\title{
Stabilization device for hydraulic drive of an electric generator on a vehicle
}

\author{
Alexander Lepeshkin ${ }^{1, *}$, Alexander Medvedev ${ }^{1}$, and Alexander Mihajlin ${ }^{1}$ \\ ${ }^{1}$ Moscow Polytechnic University, B. Semenovskaya str., 38, Moscow, 107023, Russia
}

\begin{abstract}
The paper considers the design of a hydraulic drive of an additional electric generator installed on a car, which should provide stable electrical power to consumers with standard parameters (voltage 220 (380) $\mathrm{V}$, frequency $50 \mathrm{~Hz}$ ). To solve this problem a hydraulic regulator for a hydraulic drive connected to the motor shaft of the vehicle was proposed, it automatically stabilizes the rotational speed of the hydraulic motor shaft and the generator shaft connected to it. In this case a stable frequency current by the generator is obtained. The authors carried out selection of hydraulic machines for the proposed hydraulic drive with a rated power of generated current of $8 \mathrm{~kW}$ as well as a quasistatic analysis of its operation was performed.
\end{abstract}

\section{Introduction}

Modern vehicles (TS) are increasingly equipped with auxiliary equipment, which requires 220 (380) V power supply with a frequency of $50 \mathrm{~Hz}$ for its operation.

This is due to increasing of the number of urban residents, and accordingly increasing in consumption and the provision of various services. It is also necessary to maintain housing and communal services, transport infrastructure, facilities under construction and dismantling. Separately, mobile medical complexes can be distinguished, namely: mobile sanitary and epidemiological laboratories, mobile fluorography laboratories, special vehicles that can solve medical problems in remote settlements.

At the moment there are organizations involved in the installation of such additional equipment on cars. Having visited their sites you can see the list of cars that they upgrade to meet the special needs of the customer. As a rule, companies propose installing a special petrol or diesel generator on the vehicle to power this equipment, which obviously reduces the useful capacity of the machine.

There is also a method consisting in connecting the electric generator directly to the shaft of the vehicle engine with automatic regulation of the parameters (primarily: frequency) of the generated alternating current by electronic means. It should be noted that the frequency of rotation of the engine shaft of the vehicle during its movement in the transport cycle can vary from idle speed ( $700 \mathrm{rpm}$ ) to maximum (up to $6000 \mathrm{rpm}$ ). Obviously, the main disadvantage of this option is that to ensure the required power,

\footnotetext{
* Corresponding author: a.v.lepeshkin@mospolytech.ru
} 
it is necessary to use a substantially oversized electric generator that generates the required power at the idle motion of the vehicle.

In this article, it is proposed to use a hydraulic drive between the engine shaft and the generator with stabilization of the speed of the output link [1], ensuring the constant rotation frequency of the generator shaft it will make it possible to obtain the constant frequency of the current generated by it.

The goal of the research is to develop a hydraulic controller that provides a change in the rotation frequency of the generator shaft within acceptable limits in all drive operating modes.

\section{Methods and tools of research}

Let us consider as a concrete example, where it is necessary to solve a similar problem, a refrigerated car which has an environmentally friendly small-sized air turborefrigerating system (ATRS) developed at the "Interbiznesproekt" center. This refrigerating unit statistically average consumes power supply corresponding to the sequence diagram shown in Fig 1.

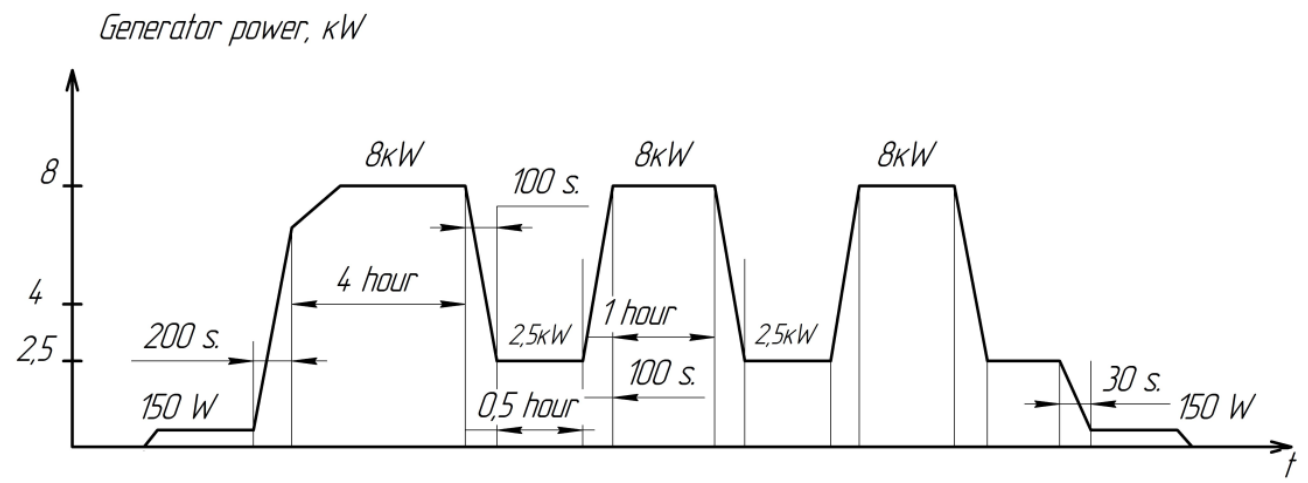

Fig. 1. The cycle diagram of the power consumption of the refrigerating unit

The maximum power $(8 \mathrm{~kW})$ of the installation is consumed when the freezer is cooled to the desired temperature. A power of $2.5 \mathrm{~kW}$ is required to maintain the required temperature in the freezer. It is clear that the moment of resistance to rotation of the generator shaft will also change in a similar way (more than 3 times). This circumstance will affect the frequency of rotation of this shaft. Therefore, the noted variability of the load on the shaft of the generator is another factor (except for the variability of the rotational speed of the engine shaft of the vehicle), which should be monitored by the stabilization system.

Considering these requirements a hydraulic drive was developed [2], the scheme of which is shown in Fig. 2.

An important feature of the proposed design is the usage of a two-section pump in it, which can significantly increase the energy efficiency of the hydraulic drive. 


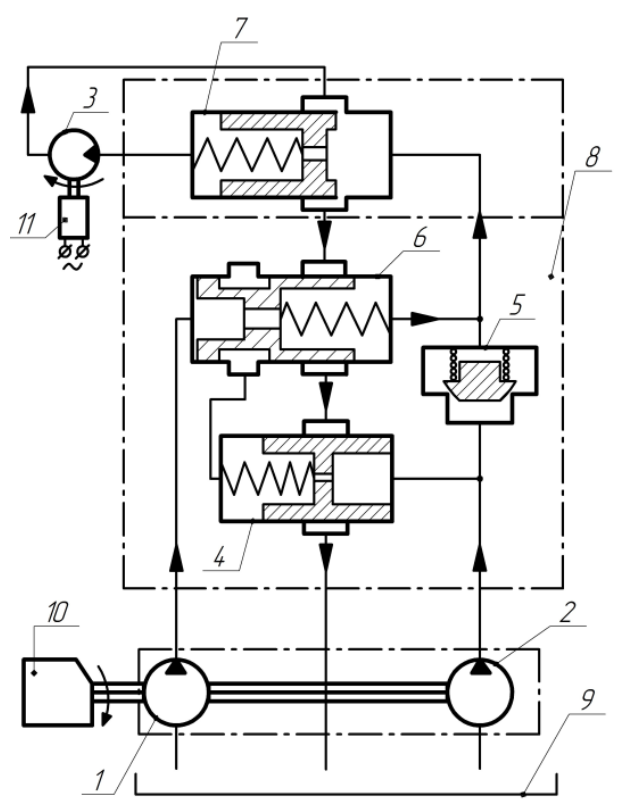

a)

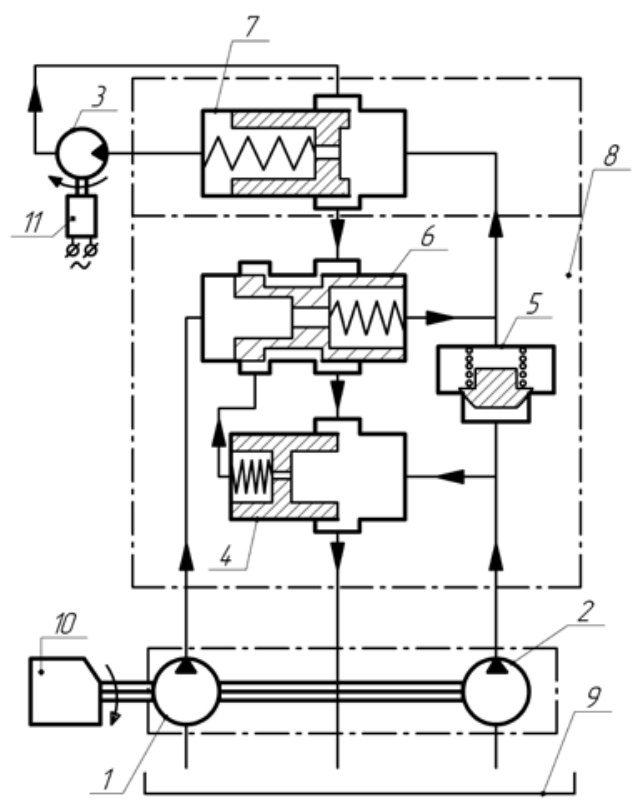

b)

Fig. 2. Hydraulic drive of the generator: a - during operation from two sections of the pump; b during operation from one pump section; 1 and 2 - the main and auxiliary sections of a two-section pump; 3 - hydromor; 4 - unloading valve; 5 - check valve; 6 - flow sensor; 7 - flow controller; 8 stabilizer, structurally combining the hydraulic units listed above in a single housing (4-7); 9 - a hydraulic tank; 10 - vehicle engine; 11 - electric generator

The operation of the hydraulic drive is the following: on changing the engine 10 revolutions, the feed of the pump sections to the pressure hydraulic line also changes. If the engine speed is such that there is a shortage of flow of the working fluid coming from the main section 1 of the pump (Fig. 2a), then the flow from it passes through the flow sensor 6 and behind the check valve 5 is combined with the flow of working fluid coming from the second (auxiliary) section 2 of the pump. At the same time the unloading valve 4 is closed, since its left cavity is closed by the spool of the flow sensor 6 , which is under the action of a spring, the force of which exceeds the force from the resulting differential pressure on the throttle of the flow sensor. The excess flow coming from two sections of the hydraulic pump is discharged by the flow regulator 7 into the tank 9. The hydraulic motor 3 through the throttle of the regulator 7 receives the fluid flow necessary to provide the required speed of the generator shaft 11 .

If the revolutions of the shaft of the engine 10 become such that the supply of the main section 1 of the pump provides the required flow rate (Fig. 2b), then under the action of the force from the pressure drop across the throttle of the flow sensor 6 , its spool, overcoming the spring force, moves to the right, opening the drain from the left cavity of the unloading valve 4 . The unloading valve 4 moves to the left, opening the drain of the liquid supplied by the pump section 2 to the tank 9 . The check valve 5 closes. The so-called unloading of the auxiliary section 2 of the pump takes place (the pressure at the outlet of this section of the pump becomes almost equal to the discharge pressure). This mode allows you to significantly reduce the power consumed by the hydraulic drive.

If in the future there is a decrease in the number of revolutions of the vehicle engine shaft, then the hydraulic drive elements return back to the position shown in Fig. $2 a$. 
To quantify the performance of the proposed hydraulic drive of its functions, the methods of quasistatic research were used. For this purpose, for him at first, according to the method described in [3], the selection of hydraulic machines was performed.

The choice was made from the conditions:

- the frequency of rotation of the shaft of the engine of the vehicle can vary from idle motion (accepted $750 \mathrm{rpm}$ ) to a maximum of $4000 \mathrm{rpm}$;

- maximum working pressure in the hydraulic system $16 \mathrm{MPa}$;

- a generator driven by a hydraulic drive must generate a maximum electric power of 8 $\mathrm{kW}$ in the form of alternating current with a frequency of $50 \mathrm{~Hz}$. The assumption was made that this frequency value would be obtained at a generator shaft speed of 3000 rpm.

From here, using the recommendations given in [1], from the catalogs $[4,5]$, an uncontrolled axial piston hydraulic motor of the 310 series (displacement $11.6 \mathrm{~cm} 3 / \mathrm{rev}$ ) and a two-section pump NS6363-32UK-3 were selected, in which the volume of the first section is $63 \mathrm{~cm} 3 /$ rev (auxiliary section), and the working volume of the second section (main section) is $32 \mathrm{~cm} 3 / \mathrm{rev}$. We also note that, as a result of the calculations, it was found that when using these hydraulic machines in the hydraulic drive in question, the auxiliary section should be switched off at a vehicle engine shaft speed exceeding $\sim 2200$ rpm.

\section{Research results}

Fig. 3 presents the results obtained on the basis of a quasistatic research, according to which the frequency of rotation of the generator shaft practically does not change within the accepted range of moment change on the generator shaft and falls within $5 \%$ of the acceptable range of frequency deviation from the accepted value.

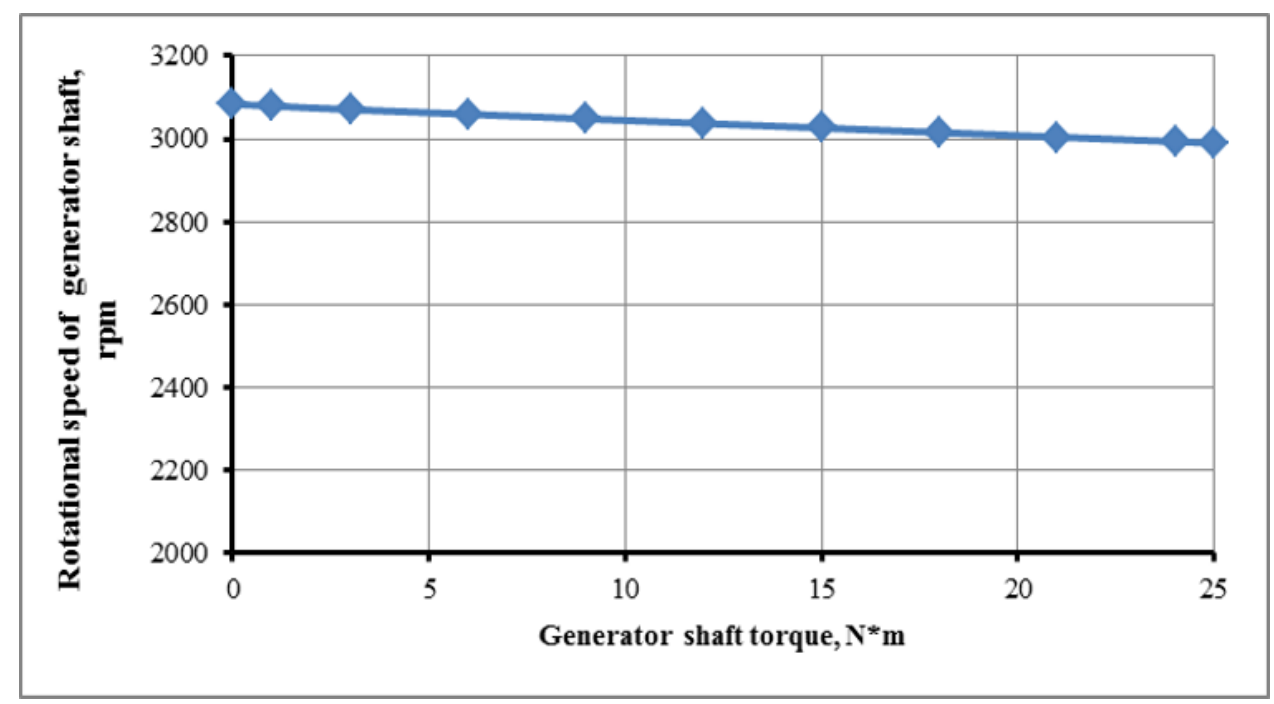

Fig. 3. The dependence of the rotational speed of the generator shaft on the load on this shaft at constant engine speeds of the vehicle

A similar result was obtained depending on the change in the rotational speed of the vehicle engine shaft. This can be seen in Fig. 4, which shows graphs characterizing the change in the rotational speed of the generator shaft as a function of changing the rotational speed of the engine shaft. From the graphs it can be seen that in the entire possible range of 
changes in the engine shaft speed, the generator shaft speed is in the allowable range of frequency deviations from the accepted value.

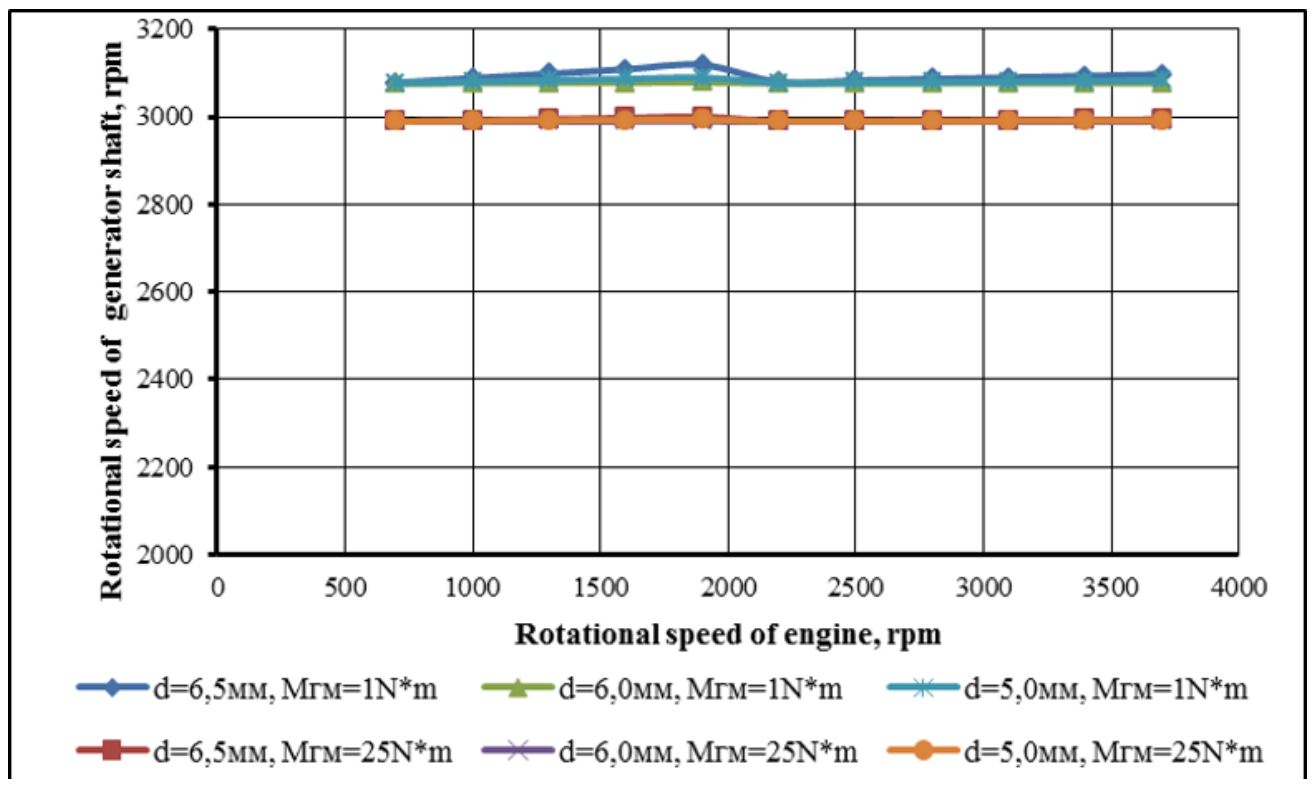

Fig. 4. The dependence of the rotational speed of the generator shaft on the rotational speed of the engine shaft of the vehicle

Fig. 4 also shows the effect of the orifice diameter of the throttle of the flow regulator 7 (see Fig. 2) on the accuracy of stabilization of the frequency of rotation of the generator shaft. We see that the control accuracy increases with decreasing diameter of the orifice of the throttle, but it is obvious that this will increase the energy loss for stabilization and, consequently, decrease the efficiency of the hydraulic drive.

The final decision on the choice of the diameter of the passage section of this throttle, as well as on other structural parameters of the proposed stabilizer 8 (see Fig. 2) will be made according to the results of the planned mathematical modeling of the proposed hydraulic drive.

\section{Conclusion}

Based on the theoretical research results, it can be concluded that the proposed structural scheme of the generator hydraulic drive provides the necessary conditional accuracy for the rotation frequency stabilization of the generator shaft both on changing the load on this shaft as well as the speed of the engine shaft of the vehicle in the considered ranges. At the same time, such a hydraulic drive will have a relatively low cost compared to that which would be when using regulated hydraulic machines in such a hydraulic drive.

Thus, the proposed design solutions are relevant, have scientific novelty and practical value in the field of transport engineering.

\section{References}

1. A.V. Lepeshkin, A.A. Mihajlin, A.A. SHejpak, Gidravlika i gidropnevmoprivod. Gidravlicheskie mashiny i gidropnevmoprivod [Hydraulics and hydropneumatic drive. 
Hydraulic machines and hydropneumatic drive] (Moscow, Infra-M Publ., 2017. 446 p.) www.dx.doi.org/10.12737/21024

2. A.V. Lepeshkin, A.S. Medvedev, A.A. Mihajlin, Hydraulic drive of auxiliary units of internal combustion engine, mainly electric generators. RF patent for useful model No. 178329 from 20.04.2017.

3. A.V. Lepeshkin, A.A. Mihajlin, A.S. Medvedev, Hydrostatic drive of the additional generator installed on the vehicle. Sbornik «Sovremennye tendencii razvitiya nauki $i$ tekhnologij». Materialy XIV Mezhdunarodnoj nauchno-prakticheskoj konferencii. Belgorod, APNI, 2016. No 5-3, pp. 99-104 (in Russ.). ISBN: 2413-0869.

4. http://www.psm-hydraulics.ru/catalog/gidromotory/nereguliruemye_motory

5. http://www.artr.ru/Gidravlik/Gidravlik_pumps/nsh/gear_sh_2nsh.htm 